\title{
SIMULATION OF THE DELIVERY SYSTEM FOR THE BICIPUMA BIKE-SHARING SYSTEM IN UNAM-MEXICO
}

\author{
García Cerrud C. ${ }^{(\mathrm{a})}$, Pérez Silva A. $\mathbf{M}^{(\mathrm{b})}$, Olvera Rodríguez V ${ }^{(\mathrm{c})}$, Soler Anguiano F.I. ${ }^{(\mathrm{d})}$, Flores de la Mota $\mathbf{I}^{(\mathrm{e})}$
}

(a) Maestría en Ingeniería de Sistemas, UNAM-MÉXICO., (b) Maestría en Ingeniería de Sistemas, UNAM-MÉXICO,

(c) Maestría en Ingeniería de Sistemas, UNAM-MÉXICO, (d) Facultad de Ingeniería, UNAM-MÉXICO, ${ }^{(e)}$ Facultad de Ingeniería, UNAM-MÉXICO.

${ }^{\text {(a) }}$ ank271704ce@gmail.com, ${ }^{(b)}$,moy132.perez@gmail.com ${ }^{(\mathrm{c})}$ olvera veronica@outlook.com $^{\text {(d) }} \underline{\text { fisau34@hotmail.com }}$ (e) idalia@unam.mx

\begin{abstract}
This paper analyzes the delivery of units by the users of Bicipuma so that the accomplishment of this task is done quickly and efficiently for the modules with the highest demand. The aim of the proposal is to create a delivery system by aids of simulation in which the times required are minimal, improving the quality of service to users.
\end{abstract}

Keywords: delivery, management, simulation.

\section{INTRODUCTION}

Growing concerns about global motorization and climate change have led to increasing interest in sustainable transportation alternatives such as bikesharing (the shared use of a bicycle fleet). Since Bikesharing's evolution is categorized into three generations: (a) white bikes (or free bike systems), (b) coin-deposit systems, and (c) information technologybased systems.

The principle of bikesharing is simple. Individuals use bicycles as-needed basis without the costs and responsibilities of bike ownership.

\subsection{History of bike sharing}

Early European bikesharing systems were small scale, operated as nonprofits, and focused on social and environmental issues.

\subsubsection{White Bikes (or Free Bike Systems): First Bikesharing Generation}

In a free bikesharing system, the bicycle is the main program component.

Other distinguishing characteristics of first-generation bikesharing were that bicycles were usually painted one bright color, unlocked, and placed haphazardly throughout an area for free use (Shahen et al., 2010).

\subsubsection{Coin-Deposit Systems: Second Bikesharing Generation}

Problems with free bike systems (namely, bike theft) led the city government and the City Bike Foundation of Copenhagen, Denmark, to launch a bikesharing service that was different from any previous system. In January 1995 Bycyken (City Bike) was launched as the first large-scale urban bikesharing program in Europe.
Bicycles were unlocked with a 20 DKK (Danish krone) coin deposit (US\$3) that was refunded on bicycle return (Shahen et al., 2010).

\subsubsection{Third-Generation Bikesharing}

The four main components of third-generation bikesharing programs are:

- distinguishable bicycles (either by color, special design, or advertisement);

- docking stations;

- $\quad$ kiosk or user interface technology for check-in and checkout; and

- $\quad$ advanced technology (e.g., magnetic striped card, smartcards).

Third-generation bikesharing programs are distinct because the incorporation of information technology has allowed bikesharing programs to track bicycles and user information. The incorporation of third-generation information technology has helped to deter bike theft, which was a major concern of second-generation coindeposit systems (Bea, 2009).

\subsubsection{Bikesharing: the present}

Since 1965 bikesharing activity has expanded to include four continents: Europe, Asia (including Australia), North America, and South America. Not surprisingly, Europe remains the leading hub for bikesharing growth, development, and success.

At present, there are approximately 101 bikesharing programs operating in an estimated 125 cities around the world, with more than 139,000 shared bicycles. As the leader in bikesharing activity today, Europe currently has 19 nations that support bikesharing (Larsen,2013).

The Americas operate programs in Canada, Mexico, the United States, Brazil, and Chile. Asia, which represents the fastest growing bikesharing market, operates programs in China, South Korea, and Taiwan.

\subsection{Bikesharing in Mexico}

In Mexico City the growth of the demographic density has become exponential and so the need for transportation, because of that the city management needed to look for a sustainable way to help with this 
mobility issues, as $50 \%$ of trips is less than 8 kilometers away, the implementation of a Bikesharing program was viable.

Therefore, the Ecobici program was created as a public bicycle system within the Integral Transportation and Roads Program (2007-2012), which was inaugurated in 2010 with 85 stations served in 6 suburbs of the Cuauhtémoc town hall, that is in the downtown area of the city. In the next years, the program expanded to the historic center of Mexico City and the Polanco neighborhood. This program was promoted as a mobility tool, which allows moving more quickly from one public transport to another or closer to its final or intermediate destinations, seeking to strengthen public transport and improving the time of transfer, road mobility and a healthier lifestyle among the citizens (Pérez López, 2017).

Mexico City launched its Ecobici program with some 1,000 bikes in 2010, it quickly reached its limit of 30,000 annual members and started a waiting list of eager would-be cyclists. The program has quadrupled in size and remains the largest of Latin America's dozen or so programs.

\subsection{Bikesharing in UNAM}

Currently, the use of alternative forms of transport is booming, especially in school campuses with large volumes of people and routes, so the central campus of the Autonomous University of Mexico created the Bicycle Loan System for those belonging to the university community called: Bicipuma.

The Secretariat of Services to the University Community, through the General Direction of Attention to the University Community, in March of the year 2005 implemented the Alternative Transportation Program "Bicipuma", to promote changes of behavior patterns in our community, directed to improve health, increasing levels of physical activity and well-being. This also reduced the congestion of vehicular traffic and its harmful effects in Ciudad Universitaria and its surroundings.

The objective of the Program is to provide the user, free of charge, the means to transfer to different educational centers and university dependencies, starting from the main accesses to the campus, to carry out their school, administrative or teaching activities, and in the free time as recreational activity. The bicycle not only allows an easy and fast displacement, but also, that the community knows different spaces of the university life is through the 5,980 meters that have of cycle path, fomenting in this way their sense of belonging, coexistence and emotional well-being.

Bicipuma has 14 stations or modules, 5980 meters of cycle path ,1440 unities that serve 4500 users daily (UNAM,2018).

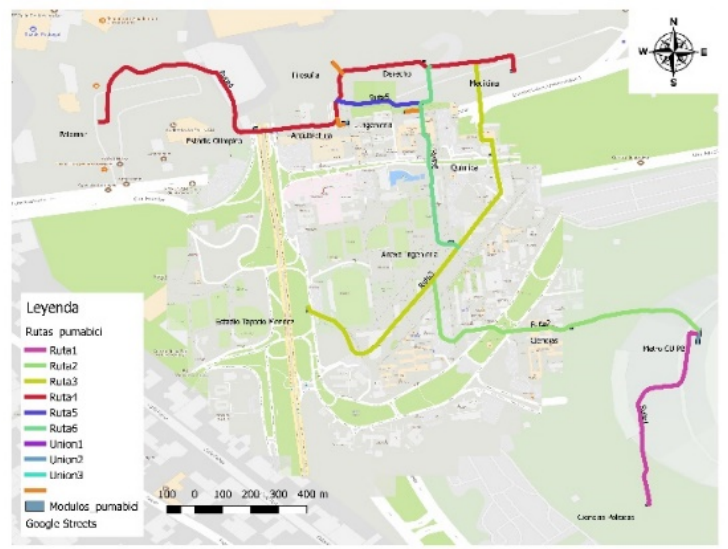

Fig. 1 Bicipuma routes.

The system in use for the loan of the bikes works in the following way: the system records the loan of bicycles, making it by the reading of the bar codes in the students or workers credential and one set on the bicycle; creating through this scan a database with the records of the account number to whom the loan is made, the date, time and exit module; the delivery of the bicycle is corroborated with the scanning of the in the delivery module, thus attaching to the database the delivery time and the module of delivery.

Damaged bicycles are collected every fifteen days for review and maintenance; the damage or wear of the mechanical parts is due to the constant use of the units. The time spent by the users regarding the delivery of the units causes a delay in the service impacting its quality and operational costs associated to the maintenance of the units.

When observing this problem, the development of a proposal that uses the existing infrastructure for the improvement of the delivery service arise.

By implementing the proposals, the delivery and service times will be improved.

This optimization will not only impact at the operating level of the system but will improve the quality of service and reduce costs associated with the maintenance of the units and modules.

This article was developed in the following way: in section two a literature review is shown. In section three the methodology used such as the data analysis, determination of the problem and determination of the proposed solution is given. Section four shows the results obtained by the followed methodology and in the fifth section conclusions are presented.

\section{LITERATURE REVIEW}

The bike sharing problem has been deeper studied in the last five years, mostly with optimization methods. In this section some papers are presented.

Maggioni et al (2019) stated that Bike-sharing systems contribute towards obtaining a more sustainable mobility and decreasing traffic and pollution caused by motorized transportation. They considered the problem faced by a bike-sharing service provider who needs to manage a fleet of bikes over a set of bike stations with 
given capacities, to serve the stochastic rental demand over space and time. A unit procurement cost is paid for each bike assigned to each station at the beginning of the service. The operational time frame is one day. The delivery of bikes to bike-stations is assumed to be instantaneous (lead time equal to zero), as this operation can be carried out before the start of the service. Backlogging is not allowed. A unit stock-out cost is paid if realized demand exceeds the number of bikes assigned to a station, and a unit transshipment cost is paid at the end of the rentals, when the bike-station inventory levels are rebalanced. The authors objective is to determine the number of bikes to assign to each bikestation at the beginning of the service, to minimize the expected total costs, given by the sum of the procurement costs, the expected stock-out costs for unmet demand, the expected time-waste costs for overflow and the expected transshipment costs for repositioning. According with this problem authors proposed a stochastic optimization model for the rebalancing issue that considers the randomness of user choices and demand over a determined space(infrastructure) and time (service hours) with the two reposition systems that exist: static repositions, and dynamic reposition. A case study is shown in Bergamo (Italy).

For Alvarez-Valdes et al (2016) the most important factor for the success of a public bike sharing system is its ability to satisfy the varying demands of the users and so the patterns of demand that must be identified and estimated and the system has to be planned and managed to maximize the level of customer satisfaction. The authors observed two key factors for this; the availability of bikes at the station and the availability of slots when the users arrive to leave the bicycle. The users must be confident that they will find bicycles to start their trips and available lockers to leave them when the trips are finished wherever and whenever they need them and proposed that for achieving such there are three phases to be considered:

1. Strategic level; the number of stations and their location and size must be decided.

2. Tactical level; the number of bicycles in the system has to be determined.

3. Operational level; a bike repositioning system has to be adopted for moving bicycles from stations with an excess to stations with a shortage in order to satisfy the demands forecast for the next periods.

The problem to be dealt with in this article is based on the second factor delimited by Alvarez-Valdes et al the availability of slots when the users arrive to leave the bicycle and in this particular case the service time associated with it which impacts directly in the system users perceived quality and since the system is meant to provide service to a specific type of users (students and faculty members) that times must be minimized in order to aid them.

Finally H.Si et al (2019) in their review paper Mapping the bike sharing research published from 2010 to 2018 : A scientometric review, show an extensive analysis of 208 articles about this topic. Based in a scientomatic analysis that can be described as a technology that demonstrates the scientific development process and structure relationship based on the knowledge domain. Based on this analysis the most significant contributions in bike sharing research primarily originated from the US, China, Canada, England and Australia. Major journals also were identified, and eight research clusters as its shown in the next figure 2 .

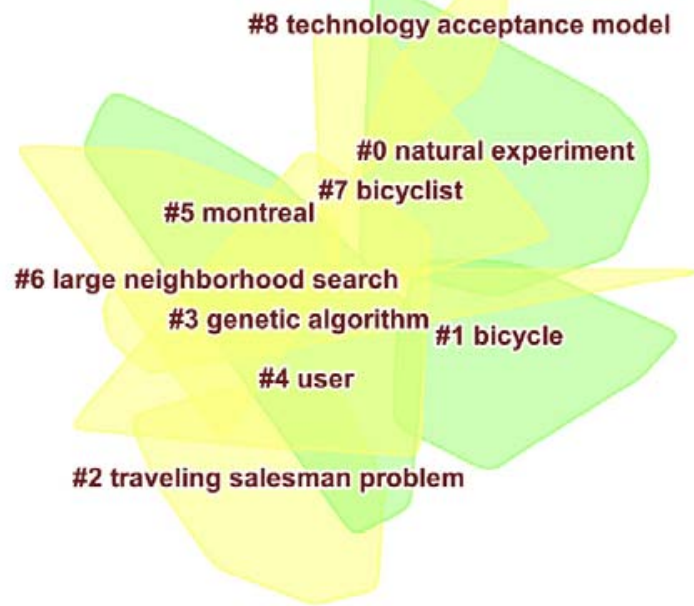

Fig. 2. Cluster analysis in the bike sharing field: 20102018. Source H. Si et al (2019)

Authors also identified based on the evolutionary trends of bike sharing research into four stages. The first stage from 2010 to 2012, focused on "safety and policy" issues. From 2013 to 2014, the second stage began to investigate the "benefit, system and impact" of bike sharing programs. Furthermore, the topics were subdivided into "optimization, behavior, built environment, design, and infrastructure", which are main research themes in the third stage of 2015. The research topics that emerged in the fourth stage (20162018) are "demand, rebalancing, redistribution, choice, weather, usage, public transport and attitude". In terms of knowledge domains, core studies on bike sharing that published from 2010 to 2018 are summarized and classified into five categories in view of different generations of programs. As for the third and fourth generations of programs, the main knowledge domains are divided into: 1) factor \& barrier; 2) system optimization; 3) behavior \& impact; 4) safety \& health. About the fifth generations of programs, the main knowledge domains are divided into: 1) factor \& barrier; 2) system optimization; 3) sharing economy. After this papers review, and mostly the last one, it can be noticed that simulation is not been used, not only for the case of the bikes delivery, but not even for the complete system. That is why is important the use of hybrid methods that consider simulation and optimization. 
In the case of our research, after making a bibliographic review of simulation methodologies and a subsequent analysis, it has been possible to develop a simulation model applied in Bicipuma delivery system. The use of discrete simulation was determined due to the fact we can define the state of the Bicipumas delivery system as the number of units in the system at a time in which the system is in state $\mathrm{n}$ in the instant $\mathrm{t}$ if at that time there are $\mathrm{n}$ units in the system, counting those waiting in line to receive service and those who are receiving service at that time.

\section{METHODOLOGY}

The methodology used for this work is the following:

\subsection{Data analysis}

The data analyzed consists of the Bicipuma loan records registered during 2016 and 2017.

With the database provided by Bicipuma, the total number of loans registered during the period from 2016 to 2017 , the day and month of greatest demand, the highest and lowest demand module.

This information was analyzed with RStudio performing a Pareto analysis and histograms of the demand, with which the modules with greater and lesser demand were determined, as well as the demand by time schedule for each one of them.

This information was used to recognize the modules that need special attention regarding times of pick-ups and deliveries. This research focused in deliveries considering the delays in this activity.

\subsection{Problem detection}

The detection of problems was carried out first through observation and direct use of the system (field work), to subsequently conduct a series of interviews with the various actors of the system including the Director of Bicipuma module managers and modules operators.

Because of the interviews we obtained that the users find the service of Bicipuma practical even though they indicate that in some cases there's a considerable delay in the service due to the inefficiency of the delivery system.

While the Director indicates that the system should have a better system in which the times and associated costs are minimized but without making a big investment.

\subsection{Determination of the study module}

The study module was determined using the data analysis described in this section even though the module is not the number one in destination demand it was selected due to its location.

The location of this module is highly important because of its proximity to one of the main entrances to the campus at the same time is located near Copilco metro station which is one of the most used means of transportation to reach the campus.

The module Medicine was selected to perform a field work in which data of variables of interest such as time of arrival and departure of the users, time in queue and time of service to be used in the simulation were collected.

\subsection{Queue theory (manual) and discrete simulation}

With the data obtained in the field work two simulations were made: a manual simulation with queue theory using excel and a simulation discrete simulation with SIMIO software, this is to make a comparison and validate the model.

For the discrete simulation it is necessary to identify the type of distribution presented by the data collected for each variable.

\section{RESULTS}

\subsection{Modules with the highest demand}

When performing the analysis of the information provided by Bicipuma, it was obtained that the module with the second highest delivery demand is Medicine as shown in the Table 1 and the histogram of these module is shown in Figure 3.

Table 1: Trip distribution for destination modules.

\begin{tabular}{|c|c|c|c|}
\hline $\begin{array}{c}\text { Destination } \\
\text { module }\end{array}$ & Nr of trips & $\begin{array}{c}\text { Relative } \\
\text { frequenc } \\
\text { y (\%) }\end{array}$ & $\begin{array}{c}\text { Accumulate } \\
\text { d frequency } \\
(\%)\end{array}$ \\
\hline $\begin{array}{c}\text { Anexo de } \\
\text { Ingeniería }\end{array}$ & 132318 & 18.0 & 18.0 \\
\hline Medicina & 114914 & 15.6 & 33.7 \\
\hline Bicicentro Pa & 7549 & 10.3 & 43.9 \\
\hline Ciencias & 68692 & 9.3 & 53.3 \\
\hline Ingeniería & 67546 & 9.2 & 62.5 \\
\hline Filosofía & 62481 & 8.5 & 71.0 \\
\hline Derecho & 46289 & 6.3 & 77.3 \\
\hline Química & 35043 & 4.7 & 82.1 \\
\hline $\begin{array}{c}\text { Estadio } \\
\text { Tapatio }\end{array}$ & 32436 & 4.4 & 86.6 \\
\hline Arquitectura & 25918 & 3.5 & 90.1 \\
\hline Bicicentro Pb & 22775 & 3.1 & 93.2 \\
\hline $\begin{array}{c}\text { Estadio } \\
\text { Olímpico }\end{array}$ & 21427 & 2.9 & 96.1 \\
\hline $\begin{array}{c}\text { Ciencias } \\
\text { Políticas }\end{array}$ & 18964 & 2.6 & 98.7 \\
\hline Palomar & 9583 & 1.3 & 100.00 \\
\hline Total & 733877 & & \\
\hline
\end{tabular}




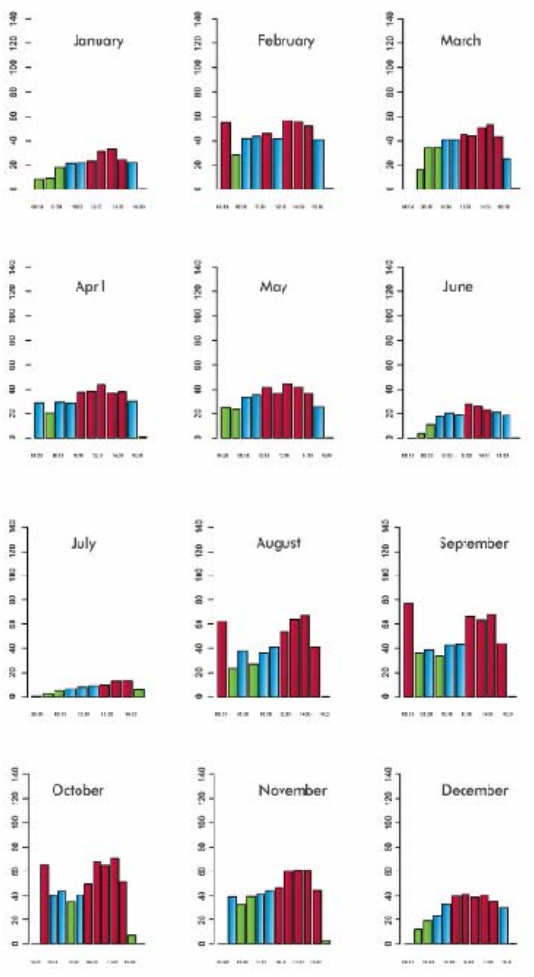

Fig. 3 Medicine module histograms

After classifying the modules, the Medicine module was selected to perform the field work and data recollection due to the reasons listed in section 3.3.

\subsection{Description of the delivery system and determination of variables}

To determine the variables a description of the delivering process was needed as well as its corresponding process flow diagram.

The delivery process flow diagram is shown in Figure 4, and function as follows: when a user arrives (start), depending on whether the operator is busy because of the demand of the module; he will wait in a queue for the entrance to the station (queuing), as the user enters the module (entering the module) its credential with which the loan of the unit (bicycle) was registered is presented (show ID card).If the credential corresponds to the user the operator scans said credential (scan ID card) and the bar code of the unit (scan Bike),then the operator checks if the unit usage time is between the regulated 20 minutes (time less than $20 \mathrm{~min}$ ) ; if not, the user is sanctioned (sanction) and if it is within the allowed time then the user proceeds to the return and accommodation of the unit (delivery, accommodation) and that concludes the process (ended service).

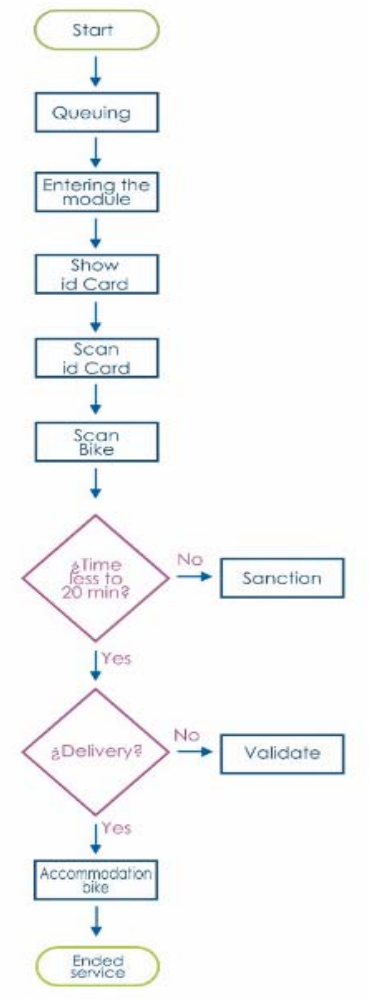

Fig. 4. Delivery process flow diagram

Then the following variables were identified:

- Attention modules.

- Module operator.

- Users.

- Bikes.

- Schedule.

- $\quad$ Times (service, row, arrivals)

\subsection{Field work data analysis}

Afterwards data collection was carried out and a total of 50 observations were taken which correspond to an hour in the system as shown in Table 2.

Table 2. Collected data from field work

\begin{tabular}{|c|c|c|c|c|c|}
\hline User & $\begin{array}{c}\text { Time } \\
\text { in } \\
\text { queue } \\
\mathrm{W}\end{array}$ & $\begin{array}{c}\text { Arrival } \\
\text { time }\end{array}$ & $\begin{array}{c}\text { Time } \\
\text { between } \\
\text { arrivals }\end{array}$ & $\begin{array}{c}\text { Service } \\
\text { time }\end{array}$ & $\begin{array}{c}\text { Exit } \\
\text { time }\end{array}$ \\
\hline 1 & 0 & 2 & 0 & 27 & 29 \\
\hline 2 & 10 & 2 & 0 & 34 & 63 \\
\hline 3 & 31 & 2 & 0 & 27 & 90 \\
\hline 4 & 13 & 23 & 21 & 22 & 112 \\
\hline 5 & 21 & 23 & 0 & 24 & 136 \\
\hline 6 & 4 & 47 & 24 & 45 & 181 \\
\hline 7 & 0 & 73 & 26 & 25 & 206 \\
\hline 8 & 14 & 78 & 5 & 33 & 239 \\
\hline 9 & 7 & 93 & 15 & 28 & 267 \\
\hline 10 & 10 & 100 & 7 & 20 & 287 \\
\hline
\end{tabular}


The analysis consists of identifying the type of distribution presented by the data collected, the data obtained from the observation was plotted.

\subsection{1.}

Times between arrivals

In Figure 5 the time between arrivals is shown, for those times, the points on the graph follow a straight line within the confidence borders and the $\mathrm{p}$ value is greater than the significance level (0.05). For these data, the distributions: normal, lognormal, exponential and Weibull do not provide an adequate fit for the data as shown in Figure 6.

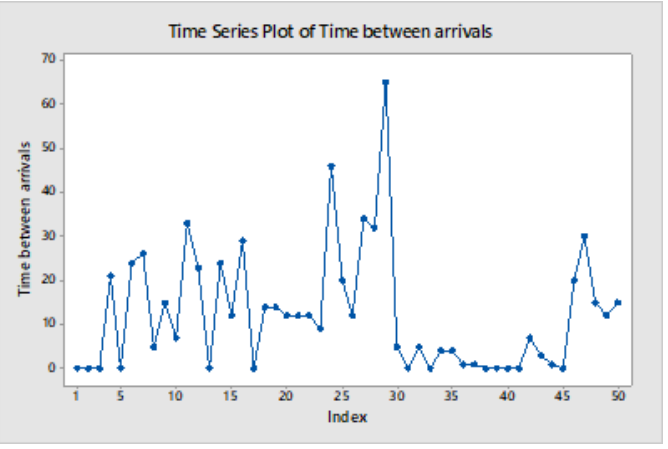

Fig. 5. Time between arrivals plot.

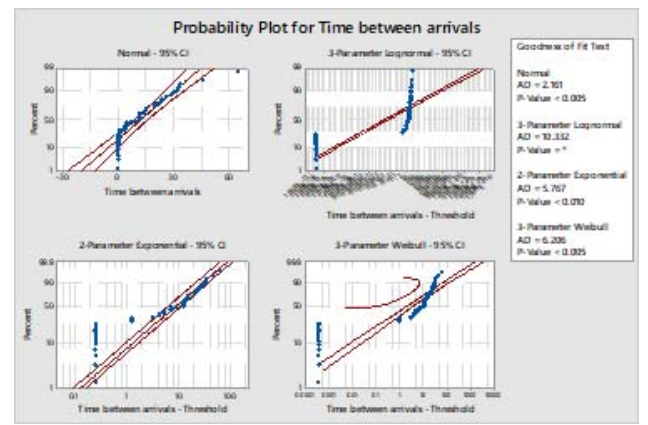

Fig. 6. Time between arrivals probability plot.

\subsubsection{Service time}

In Figure 7 the service time plot is shown, for this data the distributions: normal, lognormal, exponential and Weibull with a level of significance $(0.05)$ were plotted as shown in Figure 8, the distribution that provides a more adequate fit for the data is the lognormal.

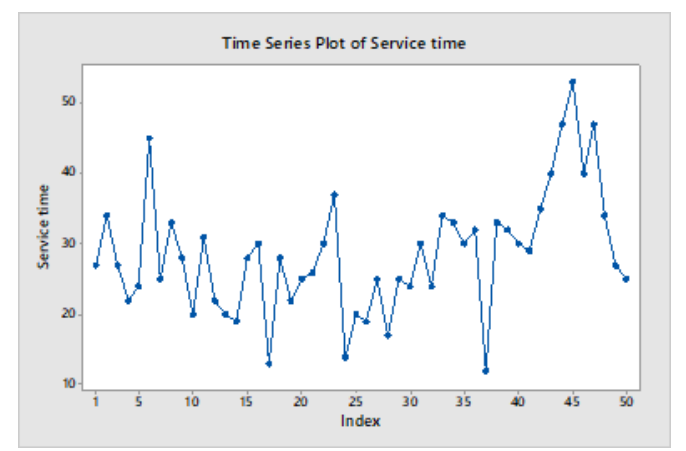

Fig. 7. Service time plot.

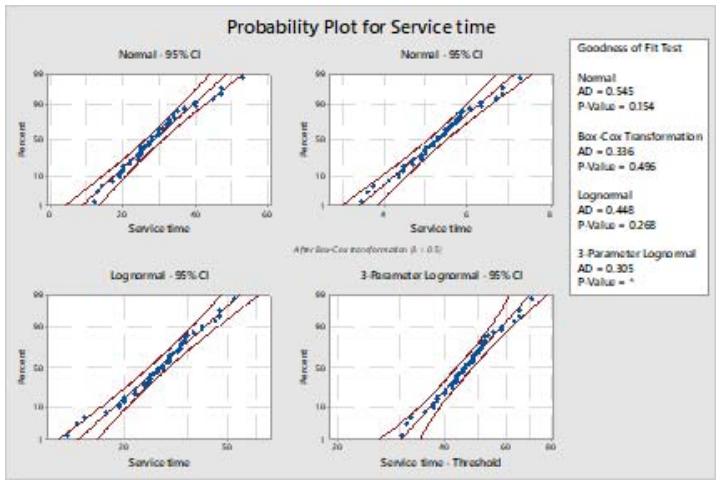

Fig. 8. Service time probability plot.

4.3.1.

Arrival time

In Figure 9 the arrival time plot is shown, for this data the distributions: normal, lognormal, exponential and Weibull do not provide an adequate fit for the data as shown in figure 10.

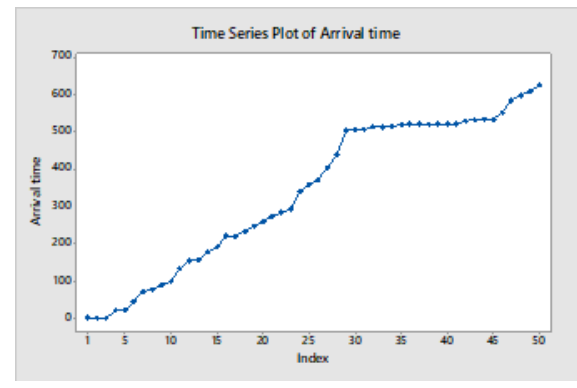

Fig. 9 Arrival time probability plot.

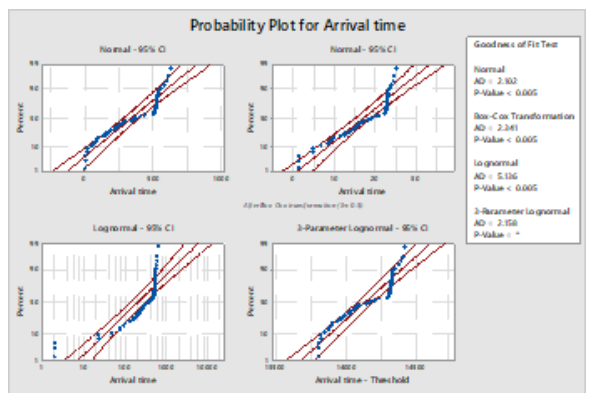

Fig. 10 Arrival time probability plot.

\subsection{Queue theory (manual simulation)}

Users who require a service (return of bicycles) enter the system and join a waiting queue. At a certain moment, a user of the queue is selected to provide the service the process is shown in Figure 11.

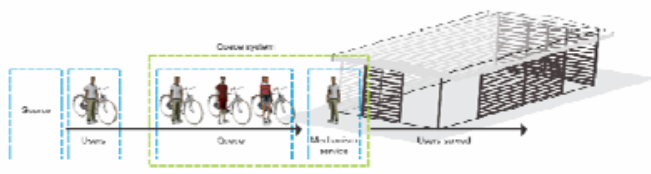

Fig. 11. Delivery service process

The basic components of the queuing process of the Bicipuma system are: 
- Input source: Finite, bounded by the number of total bicycles.

- Queue: Finite, bounded by the number of total bicycles that the module can receive.

- Discipline of the queue: The order in which users are selected to receive the service is FIFO (first input first output).

- Service mechanism: Consists of a single service installation, with a single service channel.

The data provided for this queueing process is shown in Table 3 from these the probability that there are exactly $n$ customers in the system(Pn), the expected length of the queue including users who are in service(Lq), the wait time in the queue excluding service time for each client(Wq) and the user in the average system we calculated resulting as shown in Table 4.

Table 3. Collected data from field work

\begin{tabular}{|c|c|}
\hline Arrival rate $(\lambda)$, per hour: & $\mathbf{5 0}$ \\
\hline Service rate $(\mu)$, per hour: & $\mathbf{7 0}$ \\
\hline Number of servers or channels & $\mathbf{1}$ \\
\hline
\end{tabular}

Table 4. Collected data from field work

\begin{tabular}{|c|l|l|}
\hline$L_{s}=\frac{\lambda}{\mu-\lambda}=$ & 2.5 & $\begin{array}{l}\text { Average users in } \\
\text { system }\end{array}$ \\
\hline$W_{s}=\frac{1}{\mu-\lambda}=$ & 0.05 & $\begin{array}{l}\text { Hours that the } \\
\text { average user } \\
\text { spends in the } \\
\text { whole system }\end{array}$ \\
\hline$L_{Q}=\frac{\lambda^{2}}{\mu(\mu-\lambda)}=$ & 1.786 & $\begin{array}{l}\text { Number of } \\
\text { bicycles that are } \\
\text { waiting to be } \\
\text { served by the } \\
\text { server }\end{array}$ \\
\hline$W_{Q}=\frac{\lambda}{\mu(\mu-\lambda)}=$ & 0.036 & $\begin{array}{l}\text { Average wait } \\
\text { time of a user in } \\
\text { a queue waiting } \\
\text { for the service }\end{array}$ \\
\hline$P_{0}=1-\frac{\lambda}{\mu}=$ & 0.71 & $\begin{array}{l}\text { Percentage of the } \\
\text { time the operator } \\
\text { is busy attending } \\
\text { to users }\end{array}$ \\
\hline
\end{tabular}

Figure 12 shows an example of how the manual simulation was carried out which results are shown in Table 5.

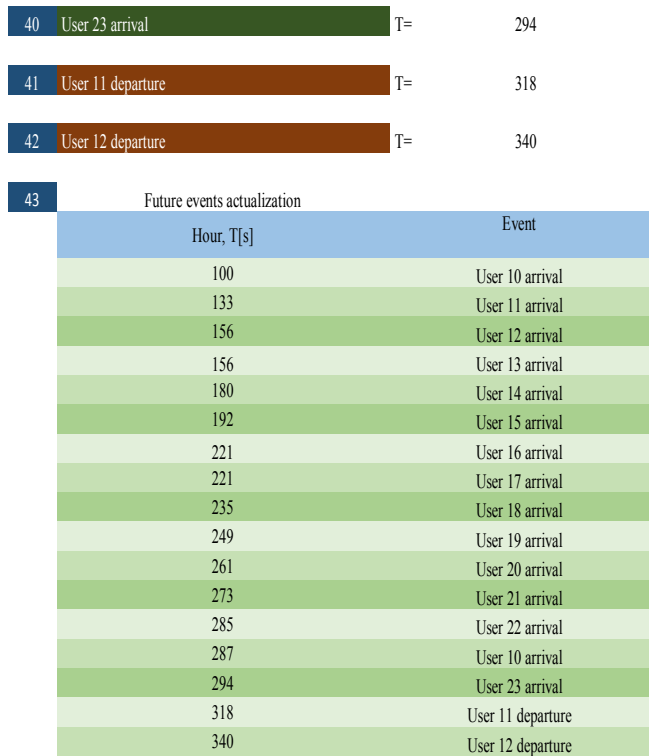

Fig. 12 Manual simulation

Table 5. Results of manual simulation

\begin{tabular}{|c|c|c|}
\hline $\begin{array}{c}\text { Average } \\
\text { queque } \\
\text { time }\end{array}$ & $\begin{array}{c}\text { Average utilization } \\
\text { of } \\
\text { installation }\end{array}$ & $\begin{array}{c}\text { Average length } \\
\text { from the queue }\end{array}$ \\
\hline 5.2773 & 99.86004199 & 11.07907628 \\
\hline
\end{tabular}

4.5. Discrete simulation (Simio Software)

This simulation was carried out in Simio Software with its corresponding distributions:

- Time between arrivals: Poisson (12)

- Arrival rate: Exponential (12)

- Service time: Exponential (12)

The distributions were selected since when testing the different distributions in the simulation those are the ones that best represent the real behavior of the system. Figure 13 shows an image of how the simulation facility was created, the user enters the loan module in which a bike is picked using a combiner both bike and user are matched, then they follow a path to the delivery facility in which by means of a separator the bike is placed in the module and the users ends the process.

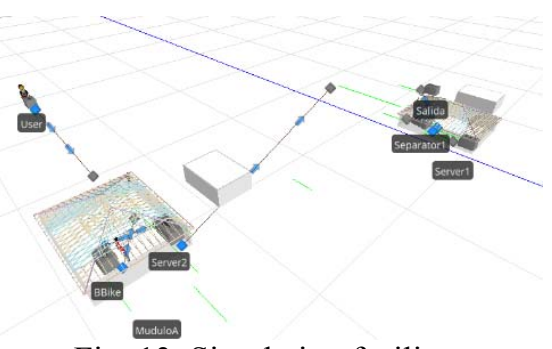

Fig. 13. Simulation facility

After running the simulation for an hour which was the time the data collection and manual simulation was made the results obtained are shown in Table 6 . 
Table 6. Results of Simio simulation

\begin{tabular}{|c|c|c|}
\hline $\begin{array}{c}\text { Average } \\
\text { queque } \\
\text { time }\end{array}$ & $\begin{array}{c}\text { Average utilization } \\
\text { of } \\
\text { installation }\end{array}$ & $\begin{array}{c}\text { Average length } \\
\text { from the queue }\end{array}$ \\
\hline 5.2773 & 99.76 & 11.07907628 \\
\hline
\end{tabular}

\subsection{Comparison of simulations}

When comparing the simulations results the difference between simulations results is minimal so we can indicate that the results are valid. The comparison is shown in Table 7.

Table 7. Comparison of simulation results

\begin{tabular}{|c|c|c|c|}
\hline $\begin{array}{c}\text { Simulation } \\
\text { Type }\end{array}$ & $\begin{array}{c}\text { Average } \\
\text { queque } \\
\text { time }\end{array}$ & $\begin{array}{c}\text { Average } \\
\text { utilization of } \\
\text { installation }\end{array}$ & $\begin{array}{c}\text { Average } \\
\text { length } \\
\text { from the } \\
\text { queue }\end{array}$ \\
\hline Manual & 5.2773 & 99.8600419 & 11.079076 \\
\hline Simio & 4.956 & 99.76 & 10.965 \\
\hline Difference & .3213 & .010004199 & .11407628 \\
\hline
\end{tabular}

\subsection{Simulation of a second scenario}

The final goal is to achieve an economic balance between the cost of service and its associated cost by waiting. The following analysis proposes to determine the number of optimal operators to attend the different schedules in the period of attention to users.

For this particular, the same medicine module will be analyzed taking the following data:

- Hours of service: 6:30 - 4:30

- Salary of the staff that attends the module: $\$$ 33.24 / hour

- User waiting time (one operator): $0.035 \mathrm{~h}$ (2.143min), calculated.

- User waiting time (two operators): $0.023 \mathrm{~h}$ (1.39min). -Estimated- (65\%)

- User waiting time (three operators): $0.014 \mathrm{H}$ (0.84 min). -Loved- (40\%)

- Average number of users: 50

With the information provided, the number of employees to be hired and their associated optimal cost will be determined to minimize the waiting time, this information is shown in Table 8.

Table 8. Information associated to costs

\begin{tabular}{|l|c|}
\hline Average users per shift & 500 \\
\hline Hours per schedule & 10 \\
\hline \multicolumn{2}{|c|}{ Average waiting time for user (minutes) } \\
\hline One operator & 2.143 \\
\hline Two operators & 1.39 \\
\hline Three operators & .84 \\
\hline Four operators & .73 \\
\hline Operator wage per hour & $\$ 33.24$ \\
\hline Operator wage per shift & $\$ 332.40$ \\
\hline
\end{tabular}

Table 9. Associated costs per number of operators

\begin{tabular}{|l|c|c|c|c|}
\hline & \multicolumn{4}{|c|}{ Number of operators } \\
\hline Concept & 1 & 2 & 3 & 4 \\
\hline $\begin{array}{l}\text { Average } \\
\text { users } \\
\text { number } \\
\text { per shift }\end{array}$ & 500 & 500 & 500 & 500 \\
\hline $\begin{array}{l}\text { Average } \\
\text { queueing } \\
\text { time per } \\
\text { users }\end{array}$ & 2.143 & 1.39 & 0.84 & 0.72862 \\
\hline $\begin{array}{l}\text { Total time } \\
\text { of } \\
\text { queueing }\end{array}$ & 1071.5 & 695 & 420 & 364.31 \\
\hline $\begin{array}{l}\text { Salary } \\
\text { cost per } \\
\text { shift }\end{array}$ & $\$ 332.40$ & $\$ 664.80$ & $\$ 997.20$ & $\$ 1,329.60$ \\
\hline $\begin{array}{l}\text { Total cost } \\
\text { per shift }\end{array}$ & $\$ 332.40$ & $\$ 664.80$ & $\$ 997.20$ & $\$, 329.60$ \\
\hline
\end{tabular}

From the previous analysis shown in Table 8 it can be seen that three operators drastically reduce the waiting time of the users of the system, however, due to the cost restriction and the limitation of the registration equipment, it is considered that the optimal number of operators per module is two, which implies a waiting time of 1.39 minutes per user with a cost of $\$ 664.80$ per working hours.

This analysis suggests the opportunity to use two operators at peak times to speed up the service loan to users.

\section{CONCLUSIONS}

Bicipuma bikesharing system is functional to its users, even though it is not in optimal service conditions due to the long waiting queues for service that occur during peak hours and in high demand modules which generates high associated costs and impacts directly in the quality of the given service.

By carrying out the simulation the problematic in the system became more evident as well as the necessity of implementing a more efficient system for the delivery of the bicycles, so the proposal of adding a second server was considered but due to the lack of resources and the cost associated with this proposal, a lower cost alternative is sought which considers the use of the existing infrastructure.

This proposal analyzes re-defining the layout in such a way that they minimize bottlenecks and, which allow users to reduce the time they perform the delivery service of bicycles, to achieve the certain areas are proposed dedicated to specific activities, these areas are as shown in Figure 14:

- Loading and unloading area: It allows to supply and collect the bicycles to the station (with the truck) 
- Bicycle delivery area: Allows the user to deliver the bicycle without "colliding" head-on with the users who come to request the loan service.

- Entry area: Allows the user to request the loan service without "crashing" with the users who deliver the bicycles.

- Exit zone: Allows the user to exit the module without "crashing" with other users (those who request the loan and those who deliver the bicycles).

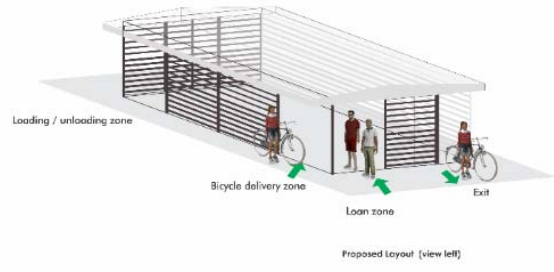

Fig. 14. Outside proposed layout

Another proposal that emerges as part of the analysis consists of the internal distribution of the module which suggests three specific zones as shown in Figure 15:

- Loading and unloading warehouse area: It allows to place the excess of bicycles that are in the module, in addition, this area will allow users who wish to choose between some of the bicycles that are found there.

- Decomposed bicycle zone: Allows the operator to place the decomposed bicycles reported by users, or that are considered to require maintenance. This area is suggested near the loading and unloading warehouse area so that the pickup truck can take them without moving in a considerable way.

- Fast service area: Allows the user to request the loan service without possibility to choose the bicycle that will be carried, the choice will be made in the order in which the bicycles are placed. Aiming to reduce the time it takes for users to choose a bicycle (either for pleasure or necessity).

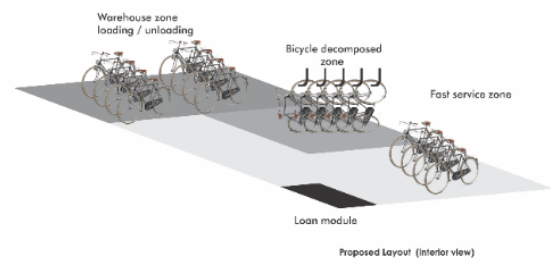

Fig. 15. Inside proposed layout

Also, the service quality will improve by not making the users wait long periods of time when delivering the bicycles and having a continuous service throughout the entire day and in the moment that it is needed.
To the PAPIIT DGAPA project IT102117, UNAM for its support to this research.

\section{REFERENCES}

Bea Alonso, M., \& Pasqual i Robert, J. (2009). Los sistemas de bicicletas públicas urbanas.

Gordillo Sotelo, C. (2016). Estado del Arte. Características y Experiencias de los Sistemas de Bicicletas Público en América Latina y Consideraciones para la Implementación del SBP en Bogotá.

Shahen Susan et al. (2010) Bike sharing in Europe, the Americas, and Asia: Past, Present, and Future.

Larsen Janet. Bike-Sharing Programs Hit the Streets in Over 500 Cities Worldwide (2013), Earth Policy Institute.

Perez López Ruth (2016). Vínculos entre la bicicleta utilitaria, recreativa y deportiva: análisis del impacto de los programas "Ecobici" y "Muévete en Bici” en la Ciudad de México (2006-2012).

Winston WL. Investigación de Operaciones. Aplicaciones y Algoritmos. 4ta ed. Stamford: Editorial Thomson Internacional; 2004.

Chase RB, Jacobs FR, Aquilano RJ. Administración de Operaciones. 12ma ed. México D.F.: McGraw-Hill Interamericana; 2009.

Shortle JF, Thompson JM, Gross D, Harris CM. Fundamentals of Queueing Theory. 5th Edition. New York: John Wiley \& Sons, Inc.; 2017.

Aspray, William. John Von Neumann and theOrigins of Modern Computing. Massachusetts. The MIT Press. p. 110-113.

Abu-Taieh, Evon M. and Rahman El Sheikh, Asim Abdel. Handbook of Research on Discrete Event Simulation Environments: Technologies and Applications. New York. Information Science Reference. p. 1.

Chung, Christopher A. Simulation Modeling Handbook, a practical approach. CRC Press. Boca Raton, FL. 2004. P3-20.

Banks, Jerry. Handbook of Simulation, principles, methodology, advances, applications and practice. Engineering \& Management Press. Toronto. 1998. P.721-745.esas, PP 208-245.

Maggioni, F. (2019). Stochastic optimization models for a bike-sharing problem with. European Journal of Operational Research, 272-283.

Si, H. (2019). Mapping the bike sharing research published from 2010 to 2018: A scientometric review. Journal of Cleaner Production, 415-427.

Valdes, R. A. (2016). Optimizing the level of service quality of a bike-sharing system. Omega, 163-175.

UNAM (2018). BICIPUMA. Dirección General de Servicios Generales y Movilidad. Retrieved from: $\mathrm{http} / / /$ dgsgm.unam.mx/bicipuma.html, on 22-052018.

\section{ACKNOLEDGMENTS}

